\title{
Indicadores de qualidade da subsolagem com escavadora hidráulica em áreas declivosas em duas diferentes umidades do solo
}

\author{
Quality indicators of subsoiling with hydraulic excavator in sloping areas at \\ two different soil moisture levels
}

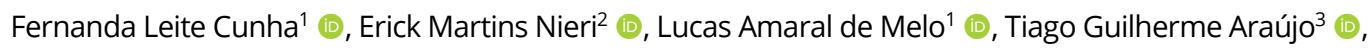 \\ Fernando Palha Leite ${ }^{3}$, Nelson Venturin ${ }^{1}$ (1) \\ ${ }^{1}$ Universidade Federal de Lavras - UFLA, Lavras, MG, Brasil \\ ¿Universidade Federal do Sul e Sudeste do Pará - UNIFESSPA, São Félix do Xingu, PA, Brasil \\ ${ }^{3}$ Celulose Nipo-Brasileira S.A. - CENIBRA, Belo Oriente, MG, Brasil
}

\begin{abstract}
Como citar: Cunha, F. L., Nieri, E. M., Melo, L. A., Araújo, T. G., Leite, F. P., \& Venturin, N. (2020). Indicadores de qualidade da subsolagem com escavadora hidráulica em áreas declivosas em duas diferentes umidades do solo. Scientia Forestalis, 48(128), e3321. https://doi.org/10.18671/scifor.v48n128.16
\end{abstract}

\begin{abstract}
Resumo
A recente adaptação do uso da escavadora hidráulica no preparo do solo em áreas declivosas, tem apresentado resultados satisfatórios, principalmente devido aos benefícios proporcionados pelo aumento da área subsolada. No entanto, ainda não se conhece a qualidade da sua execução da atividade em campo e, portanto, objetivou-se avaliar a qualidade do preparo de solo mecanizado pela haste subsoladora da escavadora hidráulica, em duas diferentes umidades de solo, por meio de indicadores de qualidade. Para isso, utilizou-se o delineamento de blocos casualizados completos, com dois tratamentos e 12 repetições. As variáveis respostas utilizadas para avaliar a qualidade do preparo do solo foram: a profundidade e a largura do sulco, a área de solo mobilizado, o formato do sulco e o índice de qualidade dos torrões (IQT). Os resultados obtidos demonstram que o solo úmido apresentou valores médios superiores para todas as variáveis, apresentando maior qualidade da subsolagem, devido a maior umidade volumétrica. O solo seco apresentou padrões de qualidade do preparo do solo, porém, o IQT foi elevado, causando inconformidades no formato do sulco, sendo este resultado relacionado, principalmente, pela escavadeira não possuir dispositivos de acabamento do sulco. Contudo, a operação de subsolagem com a escavadora hidráulica é considerada adequada para ser utilizada em áreas com 17 a $27^{\circ}$ de declividade. Portanto, recomenda-se a iniciativa/necessidade de pesquisas e estudos em novas tecnologias para promover a redução do IQT em períodos secos e aumentar a eficácia da atividade em campo.
\end{abstract}

Palavras-chave: Preparo do solo; Escavadeira hidráulica; Destorroamento do solo; Análise de qualidade.

\begin{abstract}
The recent adaptation of the use of the hydraulic excavator in the preparation of the soil in sloping areas presented satisfactory results, mainly due to the benefits provided by the increase of the sub-soiled area. However, the quality of its achievement in the field activity is not yet known and, therefore, the objective was to evaluate the quality of mechanized soil preparation by the hydraulic excavator sub-soiling rod, in two different soil moisture conditions, by means of quality indicators. For this, a complete randomized block design with two treatments and 12 replications was used. The response variables used to evaluate soil tillage quality were: furrow depth and width, mobilized soil area, furrow shape and clod quality index (IQT). The results show that moist soil resulted in higher average values for all variables, presenting higher sub-soiling quality, due to the higher volumetric humidity. The dry soil presented soil tillage quality
\end{abstract}

Fonte de financiamento: Nenhuma.

Conflito de interesse: Nada a declarar.

Autor correspondente: fernandaleitecunha@gmail.com

Recebido: 25 março 2019.

Aceito: 12 novembro 2019.

Editor: Paulo Henrique Müller Silva.

(c) (i) Este é um artigo publicado em acesso aberto (Open Access) sob a licença Creative Commons Attribution, que permite uso, distribuição e

(c) reprodução em qualquer meio, sem restrições desde que o trabalho original seja corretamente citado. 
standards, however, the IQT was high, causing non-conformities in the groove shape; this being the result related mainly to the fact that the excavator did not have furrow finishing devices. However, the subsoiling operation with the hydraulic excavator is considered suitable for use in areas with a slope of 17 to $27^{\circ}$. Therefore, the initiative / need for research and studies on new technologies is recommended to promote the reduction of IQT in dry periods and increase the effectiveness of field activity.

Keywords: Soil preparation; Hydraulic excavator; Soil disruption; Quality analysis.

\section{INTRODUÇÃO}

No setor florestal, o avanço de plantios em áreas declivosas e a mecanização de suas atividades consistem em grande desafio para a silvicultura (Pereira et al., 2012). Dentre as atividades neste setor, o preparo do solo por meio da subsolagem é a prática mais utilizada pelas empresas florestais, no entanto, apesar dos avanços tecnológicos existentes, esta é uma tarefa difícil e, muitas vezes, não tem qualidade desejada (Simões et al., 2011; Montebello \& Bacha, 2009).

A descompactação do solo, manutenção dos resíduos florestais e mobilização mecânica em profundidade nas linhas de plantio são benefícios gerados ao solo por meio da subsolagem (Simões et al., 2011; Gava, 2002). Essa prática, tornou-se fundamental para garantir maior sobrevivência das mudas, promover a homogeneidade do plantio e aumentar a produtividade da floresta (Wang et al., 2019). Para que estes ganhos sejam efetivos, faz-se necessário que esta atividade apresente elevado desempenho e um alto padrão de qualidade.

O subsolador, equipamento adaptado da agricultura na área florestal, é um implemento consolidado, devido as suas vantagens operacionais (maior capacidade de trabalho) e vantagens econômicas (menor custo) em relação a outros maquinários e ou preparo do solo manual (Sasaki \& Gonçalves, 2005). O trator de rodados acoplado a este implemento é muito empregado para a realização da subsolagem em áreas com até $17^{\circ}$ de declividade, ao passo que o conjunto máquina e implemento não possui estabilidade para trabalhar em áreas com declividades acima deste patamar (Curti \& Costa, 2013; Pereira et al., 2012). O relevo é um fator que restringe a operação de subsolagem, uma vez que declividades acentuadas, acima de $17^{\circ}$, demandam implementos adaptados, os quais apresentam desempenhos inferiores aos utilizados em áreas planas (Leite et al., 2011; Pereira et al., 2012).

Em áreas com declividade acentuada, tem-se utilizado motocoveadores, principalmente em pequenas propriedades, para o preparo do solo. Entretanto, essa atividade apresenta grande gasto energético, baixo rendimento e reduzido volume de solo mobilizado (Minette et al., 2010). Outro implemento que surge como alternativa para áreas declivosas é a escavadeira hidráulica, a qual apresenta estabilidade em terrenos com declividade elevada e são menos afetadas pela presença de tocos e resíduos da colheita, quando comparadas aos tratores de rodados acoplados com subsoladores, conforme estudos pioneiros realizados por Hall (1995) e Souza et al. (2018).

A subsolagem apresenta um elevado gasto energético e custo para as empresas, sendo necessário realizá-la em conformidade com padrões de qualidade para garantir ganhos em homogeneidade, produtividade e lucratividade em plantios florestais (Salvador et al., 2008; Simões et al., 2011).

O uso da escavadora hidráulica para o preparo do solo e o controle da qualidade florestal são recentes e de caráter inovador. Portanto, torna-se essencial práticas voltadas para averiguação da qualidade das atividades florestais, uma vez que estas auxiliam na otimização dos recursos naturais e financeiros, evitando perdas e desperdícios (Trindade \& Melo, 2016).

Os estudos abordando a mecanização da silvicultura em áreas declivosas são escassos, o que torna relevante a pesquisa com a escavadora hidráulica nestas condições. Neste contexto, nota-se a importância de avaliar a qualidade do seu desempenho para entender e conhecer o seu potencial, padronizar suas atividades e otimizar sua operação em campo. No entanto, ao realizar a subsolagem com a escavadora hidráulica em áreas acima de $17^{\circ}$ de declive, espera-se que a qualidade da mobilização do solo não seja alterada nas diferentes condições de umidade. Dessa forma, objetivou-se avaliar a qualidade da subsolagem 
realizada pela haste da escavadora hidráulica e a influência de diferentes umidades volumétricas na atividade.

\section{MATERIAL E MÉTODOS}

A área experimental, localiza-se na região de Nova Era - MG $\left(19^{\circ} 45^{\prime} 00^{\prime \prime} \mathrm{S}\right.$ e $43^{\circ} 02^{\prime}$ $15^{\prime \prime}$ W), Brasil, com topografia predominantemente montanhosa, Cambissolo Háplico textura média argilosa, com densidade média de $1,2 \mathrm{~g} \mathrm{~cm}^{-3}$, e clima classificado por Köppen como CWa (Alvares et al., 2013). As médias de precipitação para região meses nos de maio a setembro, caracterizado como período seco, é de $21,8 \mathrm{~mm}$ mensais, enquanto para os meses de novembro a abril, caracterizado como período úmido, é de $274 \mathrm{~mm}$ mensais (Souza et al., 2003).

O local de estudo continha um povoamento de híbrido de Eucalyptus grandis x Eucalyptus urophylla com sete anos de idade e em arranjo de $3 \times 2 \mathrm{~m}$. Estes foram colhidos por meio do sistema de toras curtas (cut-to-length), o qual compreendeu na derrubada, desgalhamento, e no descascamento e traçamento da madeira, sendo estes processos realizados por Harvester e, posteriormente, fez-se o baldeio da madeira até a estrada por meio do Forwarder. Após a colheita e retirada da madeira, os resíduos permaneceram na área para a instalação do ensaio experimental.

O experimento foi conduzido em delineamento de blocos casualizados completos (DBCC), composto por dois tratamentos (subsolagem com o solo seco e úmido), em 12 blocos, sendo o bloco composto por uma parcela de cada tratamento. A parcela foi instalada sobre uma linha de preparo de solo, sendo considerados $10 \mathrm{~m}$ de comprimento e $1 \mathrm{~m}$ para cada lado da linha.

Após a definição dos blocos e aleatorização dos tratamentos, foi realizado o preparo do solo. Os tratamentos com solo seco foram subsolados no mês de setembro, com precipitação média de $35 \mathrm{~mm}$, enquanto os tratamentos com o solo úmido foram subsolados no mês de novembro, com precipitação média de $236 \mathrm{~mm}$ (Souza et al., 2003).

A escavadora hidráulica utilizada para a realização da subsolagem foi a Caterpilar modelo $312 \mathrm{DL}$, motor com potência líquida de $72,3 \mathrm{~kW}$, peso de 13 t., largura entre as esteiras de 3,2 m e comprimento do braço de 6,5 m. Na ponta do braço hidráulico da escavadora foi adaptada uma haste subsoladora, em substituição ao conjunto original com caçamba, para a realização de sulcos e subsolagem do terreno para plantio. A haste apresenta altura máxima de 1,0 m e possui ponteira com abas laterais, com 0,2 $\mathrm{m}$ de largura. A subsolagem foi realizada a uma distância de três metros entre linhas, em sentido perpendicular à inclinação do terreno (Figura 1).

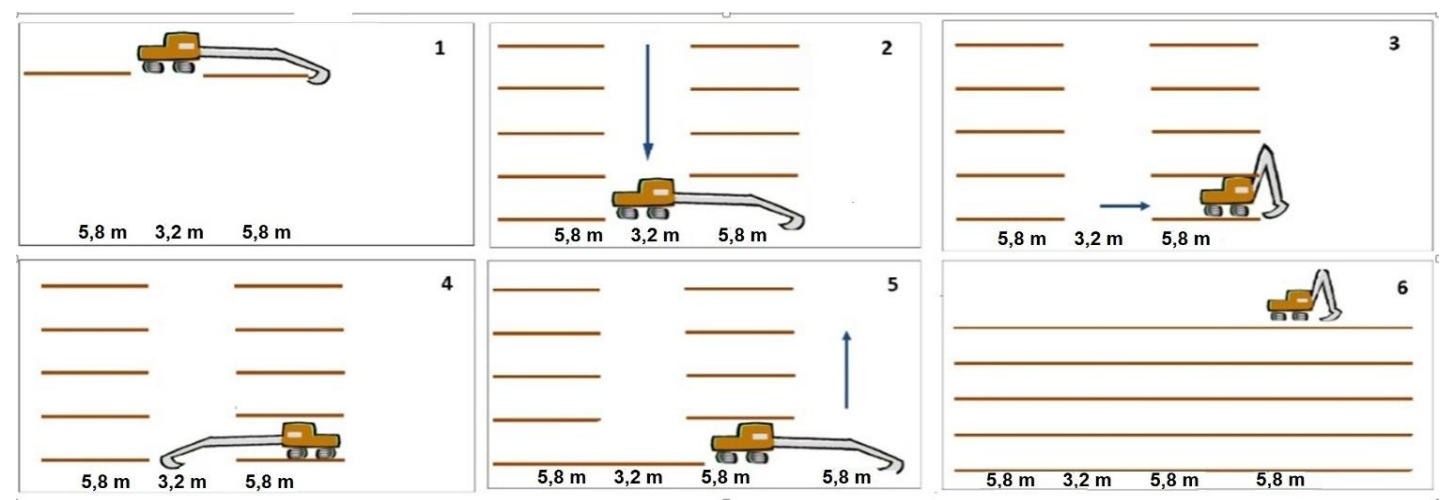

Figura 1 - Sequência de deslocamento e operação de subsolagem pela escavadora hidráulica na área.

$\mathrm{Na}$ subsolagem, foram consideradas como especificações mínimas para a seção confeccionada, 0,40 $\mathrm{m}$ de profundidade, 0,60 $\mathrm{m}$ de largura e de 0,12 $\mathrm{m}^{2}$ de área de solo mobilizado, atingido uma conformação em "V", baseadas nos trabalhos de Fessel (2003) e Barros (2001), (Figura 2). 


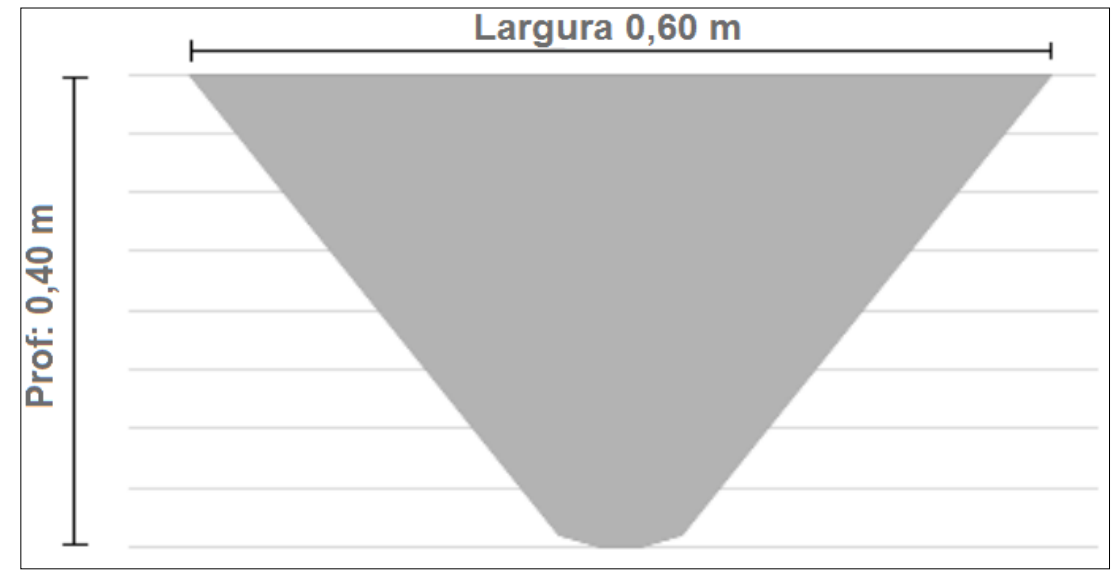

Figura 2 - Especificação para confecção do sulco na operação de subsolagem pela escavadora hidráulica, de formato em "V", com profundidade de 0,40 m, largura de 0,60 m, e área de solo mobilizada de aproximadamente $0,12 \mathrm{~m}^{2}$.

Os dados de cada parcela foram obtidos pela média de três pontos de análise. As variáveis respostas utilizadas para os indicadores de qualidade estipulados foram: a profundidade e largura do sulco, a área de solo mobilizado, o formato do sulco e o índice de qualidade dos torrões (IQT). Ademais, para confirmar o efeito dos períodos e explicar o comportamento dos indicadores, foi realizada a coleta da umidade do solo no momento da realização do preparo.

A largura do sulco foi avaliada por meio de uma haste, a qual foi inserida na parede do sulco e sua distância medida por uma fita métrica para delimitar a distância entre suas extremidades. No mesmo ponto em que foi obtida a largura do sulco, realizou-se a avaliação das profundidades alcançadas pela atividade de subsolagem, por meio do perfilômetro disposto perpendicularmente a subsolagem realizada, o qual é um equipamento composto por uma barra na base, de 0,81 m de comprimento, com 28 hastes de um metro de altura, distanciadas em três centímetros entre si (Figura 3).

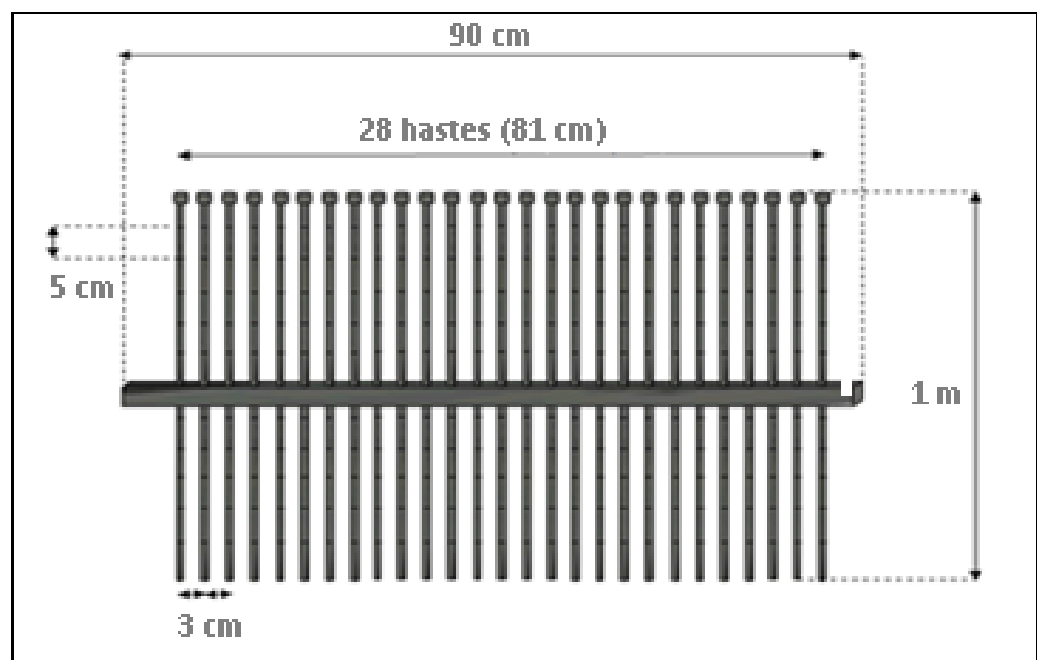

Figura 3- Representação do equipamento perfilômetro.

As alturas das hastes foram mensuradas por uma fita métrica e plotadas em gráficos, para a obtenção do perfil do solo mobilizado. Para encontrar a área de solo mobilizado, fezse o somatório das médias entre duas hastes, multiplicado por 0,03 m (distância entre as hastes). $O$ formato do sulco foi analisado por meio das especificações de subsolagem, de 0,40 de profundidade, 0,60 de largura e 0,12 $\mathrm{m}^{2}$ de área de solo mobilizado, em que os gráficos 
gerados foram classificados como, conformes, quando atingiam a mobilização mínima especificada na Figura 2, ou não conformes, quando não atingiam as especificações indicadas.

Para avaliar a qualidade do acabamento do sulco, realizou-se a análise do nível de destorroamento pelo implemento. Para isso, utilizou-se um quadrante de 0,50 x 0,50 m, alocado ao lado do perfilômetro. Na área interna do quadrante, foram avaliados dois índices: Índice do Número de Torrões (INT) e Índice do Diâmetro dos Torrões (IDT). Para facilitar as análises qualitativas, foi criado o Índice de Qualidade dos Torrões (IQT), que é a multiplicação entre o IDT e o INT (Tabela 1). O valor considerado como ideal de IQT foi baseado em observações em campo, e no trabalho de Barros (2001), em que foi considerado como ideal, diâmetros inferiores a $0,10 \mathrm{~m}$. Desta forma, os valores de IQT considerados como ideais, com bom índice de destorroamento do solo, foram aqueles índices que ficaram abaixo de 4.

Tabela 1-Índice do Diâmetro dos Torrões (IDT), Índice do Número de Torrões (INT) utilizado para avaliação qualitativa das amostras.

\begin{tabular}{cccc}
\hline IDT & Diâmetro dos torrões $(\mathbf{c m})$ & INT & Número de torrões \\
\hline 1 & $<0$ & 1 & 0 \\
2 & $0-5$ & 2 & $0-5$ \\
3 & $5-15$ & 3 & $5-10$ \\
4 & $15-30$ & 4 & $10-15$ \\
5 & $>30$ & 5 & $>15$ \\
\hline
\end{tabular}

Fonte: Autor (2019)

A umidade volumétrica do solo foi mensurada de acordo com a Empresa Brasileira de Pesquisa Agropecuária (1997), por meio da coleta de amostras retiradas por um anel volumétrico de inox, com aproximadamente $0,03 \times 0,025 \mathrm{~m}$ de altura e diâmetro, respectivamente, e volume $(\mathrm{V})$ de $1,4 \times 10^{-5} \mathrm{~m}^{3}$, na profundidade de $0-0,20 \mathrm{~m}$. As amostras foram coletadas nas entrelinhas, próximo a cada ponto amostral de cada parcela. Para a obtenção da umidade do solo, pesou-se as amostras, peso úmido (PU), e foram colocadas em estufa de circulação forçada de ar e, temperatura de $105^{\circ} \mathrm{C}$, até atingir peso constante, para obtenção do peso seco (PS). A umidade foi calculada da seguinte forma: $\mathrm{U}=(\mathrm{PU}-\mathrm{PS}) / \mathrm{V} * 100$.

As médias obtidas pelos indicadores de qualidade foram submetidas ao teste de normalidade, Shapiro Wilk (Royston ,1983) e, quando verificada a distribuição normal, as médias foram submetidas a análise de variância (ANAVA). Quando significativo, realizou-se o teste de Fisher $(F)$ a $1 \%$ de probabilidade de erro. As análises foram realizadas por meio do Sisvar 5.6 (Ferreira, 2011). Ademais, realizou-se a correlação de Pearson para profundidade do preparo, largura do sulco, área de solo mobilizada, IQT, umidade e densidade, sendo considerado $r=0$ (ausência de correlação), $0<r<0,3$ (correlação fraca); $0,3 \leq r<0,6$ (correlação regular); $0,6 \leq r<0,9$ (correlação forte); 0,9 $r<1$ (fortemente correlacionado) e $r=1$ (correlação perfeita) (Callegari-Jacques, 2003; Figueiredo Filho \& Silva Júnior, 2009).

\section{RESULTADOS E DISCUSSÃO}

Na Tabela 2, pode-se observar que o preparo do solo realizado em diferentes condições de umidades do solo apresentou resultados significativos para área do solo mobilizado, profundidade do sulco, largura do sulco, índice de qualidade dos torrões e umidade do solo.

Observa-se na Tabela 3 que a mobilização do solo úmido $\left(0,41 \mathrm{~m}^{2}\right)$ apresentou resultados superiores aos encontrados no solo seco $\left(0,27 \mathrm{~m}^{2}\right)$. Estes resultados se assemelham aos encontrados para a profundidade do sulco e largura do sulco, sendo verificados $0,76 \mathrm{~m}$ e 1,00 $\mathrm{m}$ para o solo úmido e $0,64 \mathrm{~m}$ e $0,58 \mathrm{~m}$ para o solo seco, respectivamente. Para a umidade 
volumétrica do solo, observa-se que o solo úmido $(23,10 \%)$ apresentou resultados superiores ao solo seco $(17,23 \%)$.

Tabela 2- Resumo da Análise de Variância da influência da condição do solo úmido e seco sobre os indicadores de qualidade no preparo do solo com a escavadora hidráulica.

\begin{tabular}{ccccccc}
\hline \multirow{2}{*}{ Fonte de Variação } & \multicolumn{7}{c}{ QUADRADO MÉDIO } \\
\cline { 2 - 7 } & $\mathbf{G L}$ & $\mathbf{A S}\left(\mathbf{m}^{\mathbf{2}}\right)$ & Prof $(\mathbf{m})$ & $\mathbf{L}(\mathbf{m})$ & IQT & U (\%) \\
\hline Condição do solo & 1 & $0,112^{*}$ & $0,091 *$ & 1,058 * & $240,663^{*}$ & $156,460 *$ \\
Bloco & 11 & $0,008 \mathrm{~ns}$ & $0,018 \mathrm{~ns}$ & $0,020 \mathrm{~ns}$ & $7,400 \mathrm{~ns}$ & $6,020 \mathrm{~ns}$ \\
Erro & 11 & 0,004 & 0,014 & 0,020 & 9,123 & 1,122 \\
CV (\%) & - & 20,12 & 17,39 & 20,110 & 54,09 & 5,23 \\
Médias & - & 0,34 & 0,70 & 0,80 & 5,58 & 20,30 \\
Desvio Padrão & - & 0,11 & 0,14 & 0,27 & 4,18 & 2,74 \\
\hline
\end{tabular}

em que: GL: graus de liberdade; AS: área de solo mobilizado (m²); Prof: profundidade do sulco (m); L: largura do sulco (m); IQT: Índice de Qualidade dos Torrões; U: umidade volumétrica do solo (\%); CV: coeficiente de variação; *: diferença significativa entre as médias, a $1 \%$ de probabilidade do erro; ns: sem diferença significativa entre as médias, a $1 \%$ de probabilidade do erro.

Ao verificar o resultado do IQT, nota-se que, em média, o valor encontrado para o solo úmido $(2,27)$ foi inferior ao encontrado para o solo seco $(8,75)$, ao passo que quanto menor a média, menor a incidência de torrões no solo. Dessa forma, constata-se que apenas no período úmido alcançou média adequada para o destorroamento do solo.

Tabela 3- Médias da área mobilizada (AS), profundidade (Prof), largura do sulco (L), Índice de Qualidade dos Torrões (IQT) e a umidade volumétrica (U) atingida pelo preparo do solo realizado pela Escavadora Hidráulica, em diferentes condições de umidade do solo.

\begin{tabular}{cccccc}
\hline Condição do solo & AS $\left.\mathbf{( m}^{\mathbf{2}}\right)$ & Prof $(\mathbf{m})$ & $\mathbf{L}(\mathbf{m})$ & IQT & U (\%) \\
\hline Seco & $0,27 \mathrm{~b}$ & $0,64 \mathrm{~b}$ & $0,58 \mathrm{~b}$ & $8,75 \mathrm{~b}$ & $17,23 \mathrm{~b}$ \\
Úmido & $0,41 \mathrm{a}$ & $0,76 \mathrm{a}$ & $1,00 \mathrm{a}$ & $2,41 \mathrm{a}$ & $23,10 \mathrm{a}$ \\
\hline
\end{tabular}

Médias seguidas por mesma letra, na coluna, não diferem entre si, pelo teste $F$, a $1 \%$ de probabilidade de erro.

Ao verificar o formato do sulco, nota-se que em todas as parcelas avaliadas no período úmido foi atingido o mínimo de área de solo mobilizada recomendado, enquanto, no período seco, em $45 \%$ das parcelas avaliadas, o mínimo recomendado não foi obtido (Figura 4).
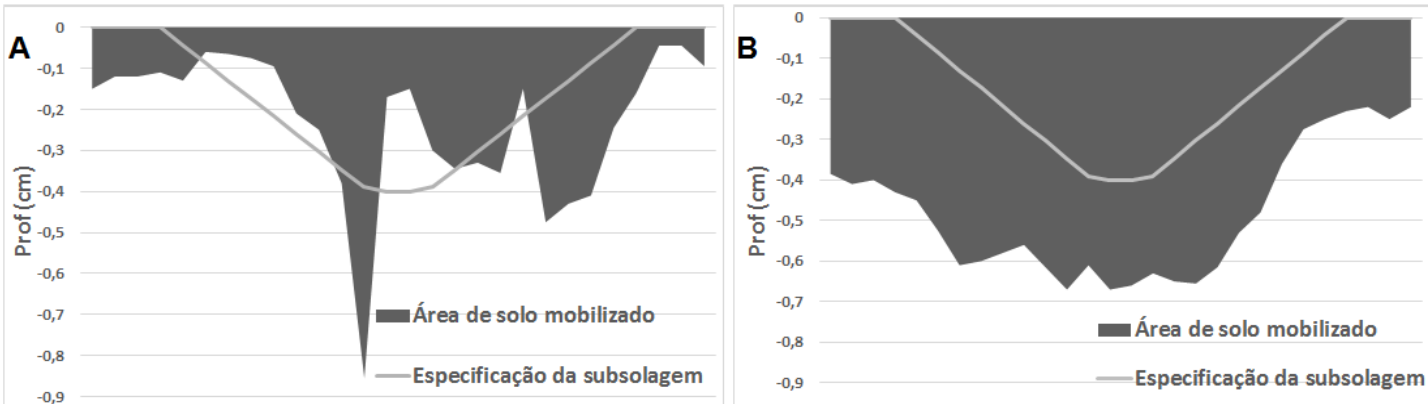

Figura 4 - Formato do sulco obtido na subsolagem realizada pela escavadora hidráulica, em parcela no solo seco (A), de obtendo profundidade máxima $0,85 \mathrm{~m}$ e área de solo mobilizada de $0,19 \mathrm{~m}^{2}$, e em úmido parcela no período (B), obtendo profundidade máxima de $0,66 \mathrm{~m}$ e área de solo mobilizado de $0,40 \mathrm{~m}^{2}$.

Ao realizar a correlação de Pearson (Tabela 4), pode-se verificar que as correlações positivas regulares foram encontradas entre umidade e área de solo mobilizado $(0,52)$, umidade e 
profundidade $(0,39)$ e profundidade e largura $(0,57)$. As correlações positivas fortes foram verificadas entre umidade e largura $(0,61)$, profundidade e área de solo $(0,75)$, e largura e área de solo mobilizado $(0,75)$. As demais correlações foram negativas, ou seja, as variáveis são inversamente proporcionais, ao passo que estas apresentam interação regular entre o IQT e a profundidade $(-0,40)$ e entre o IQT e a largura $(-0,56)$, enquanto, as correlações negativas fortes foram entre a umidade e o IQT $(-0,80)$ e para o IQT e a área de solo mobilizado $(-0,70)$.

Tabela 4 - Correlação de Pearson entre as variáveis de profundidade (Prof), largura do sulco (L), área de solo mobilizado (AS), índice de qualidade dos torrões (IQT), e a umidade volumétrica para o preparo do solo realizado pela escavadora hidráulica na região de Nova Era - MG.

\begin{tabular}{cc}
\hline Interações & Correlação de Pearson \\
\hline U x AS & 0,52 \\
$U \times$ Prof & 0,39 \\
$U \times L$ & 0,61 \\
U x IQT & $-0,80$ \\
IQT x Prof & $-0,40$ \\
IQT X AS & $-0,70$ \\
IQT x L & $-0,56$ \\
Prof X AS & 0,75 \\
Prof X L & 0,57 \\
Lx AS & 0,75
\end{tabular}

Em que: AS: área de solo mobilizado; Prof: profundidade do sulco; L: largura do sulco; IQT: índice de qualidade dos torrões.

As diferentes médias obtidas para a profundidade e a área de solo mobilizado, entre os períodos seco e úmido corroboram com os autores Sasaki \& Gonçalves (2005), os quais salientam que a mobilização do solo é maior com o aumento da umidade. Logo, à medida que se eleva a umidade do solo, nota-se que ocorre aumento da eficiência de mobilização, sendo esta constatada pela alta correlação verificada entre a umidade do solo e a área de solo mobilizado, assim como observado por Almeida et al. (2008).

No entanto, existe um limite para o aumento de umidade, sendo que para solos encharcados essa relação não se aplica, pois o preparo do solo se torna ineficiente pelo efeito da lubrificação da água que causa o aumento da compactação do solo (Volpato et al., 2004). Segundo Cassel (1979) e Volpato et al. (2004), o ideal é realizar a subsolagem quando os solos se encontram com consistência caracterizada como friável, ou seja, seus torrões podem ser facilmente rompidos em frações menores entre os dedos.

No presente estudo, o solo de toda a área experimental foi caracterizado como Cambissolo háplico textura média argilosa, com densidade de $1,2 \mathrm{~g} \mathrm{~cm}^{-3}$. Nestas condições foi observado que o solo úmido, mesmo ainda não estando na consistência caracterizada como friável, apresentou umidade de $23,10 \%$, valor superior à umidade encontrada no solo seco e suficiente para que a atividade de subsolagem com a escavadora hidráulica pudesse ser considerada como satisfatória, atingindo a qualidade exigida. Sasaki e Gonçalves (2005), relatam que em Latossolos vermelhos distrófico, os teores de umidade entre 50 a $60 \%$ da capacidade de campo propiciaram melhores resultados operacionais e a qualidade técnica do preparo de solo, utilizando-se subsolador acoplado em trator de rodados, ao contrário do obtido no presente trabalho, uma vez que as características físicas do solo são distintas.

De acordo com Rossetti \& Centurion (2015) solos em condição de friabilidade, apresentam resultados satisfatórios para sua mobilização, o que justifica o padrão de qualidade obtido pelo preparo do solo úmido, em relação ao solo seco. Apesar dos solos friáveis favorecerem a mecanização, essa faixa de umidade apresenta valores de máxima compactação. Este fato foi considerado por Silva et al. (2010), como uma das possíveis causas do incremento da degradação física em diversos solos agrícolas e em diferentes classes de solos. 
Ao realizar o preparo do solo com escavadora hidráulica no solo úmido, verifica-se que a mobilização do solo em área e profundidade são superiores ao recomendado, como observado na Tabela 3, uma vez que o solo apresenta maior umidade volumétrica. Esse resultado, ocorre por este implemento possuir elevada potência e força mecânica, por ser adaptado da engenharia civil. Segundo Lani \& Bragança (2017), o preparo do solo com a escavadora, atinge profundidades entre 0,60 e 0,80 m, o que corrobora com Gadanha Júnior et al. (1991), que considera que o limite para a atividade é de até 0,80 m, uma vez que profundidades superiores podem ocasionar lixiviação e erosão do solo.

Ao observar os resultados obtidos, nota-se valores superiores ao recomendado e com alto desvio padrão dos dados $(0,14 \mathrm{~m})$, ou seja, a atividade desempenhada pela escavadora necessita de melhorias nos padrões de profundidade, uma vez que Machado et al. (2015), testando o efeito da realização da subsolagem por subsoladores, encontraram que a variação da profundidade atingida gerou a elevação no custo da atividade. Dessa forma, a adoção de sistemas de precisão para controlar a profundidade da haste na subsolagem, pela escavadora hidráulica em campo, são indicados para aumentar a eficiência da operação (Trindade \& Melo, 2016).

A correlação entre a profundidade e as variáveis IQT e a umidade foram classificadas como regulares, o que indica que a profundidade do solo também varia em função de fatores pontuais, sendo estes os resíduos da colheita florestal e as raízes. Estes fatores e a alta incidência de torrões, também influenciam no formato do sulco e aumentam o IQT.

A correlação entre o IQT e a umidade do solo foi negativa e alta, o que ressalta que quanto menor a umidade do solo, maior é a incidência de torrões, de modo a justificar o encontrado no período úmido, em que o parâmetro se encontrou abaixo do limite máximo recomendado (4), enquanto no período seco, a média encontrada foi de 8,75, valor considerado elevado.

A menor umidade encontrada nas parcelas no solo seco influenciou positivamente na maior incidência de torrão, uma vez que este ocorre pelo aumento da coesão do solo e da cimentação de suas partículas. Dessa forma, o corte é feito com maior eficiência nos pontos de cisalhamento do solo e, consequentemente, provoca um aumento da incidência de torrões (Baver \& Gardner, 1972).

O IQT apresentou alta correlação negativa com a área de solo mobilizado e a largura do sulco, de modo a vislumbrar que a ocorrência de torrões no solo atuou como uma barreira física à introdução da haste do perfilômetro no solo, na aferição da variável. Dessa forma, mesmo que a haste subsoladora da escavadora atinja a profundidade recomendada para a atividade, os torrões formados, possivelmente reduzem a área de solo mobilizado, que estaria disponível para o crescimento radicular. O autores Queiroz-Voltan et al. (2000) salientam que a alta incidência de torrões reduz o desenvolvimento de raízes laterais, causa alterações morfológicas nas raízes e reduz a quantidade de nutrientes, água e oxigênio disponíveis para a planta, o que proporciona um aumento no índice de mortalidade de mudas em campo.

Em períodos de baixa umidade, segundo Theodoro et al. (2018), são necessárias várias operações, para culturas agrícolas, com a grade niveladora, para realizar um bom acabamento do sulco, reduzindo a quantidade e tamanho de torrões. De modo geral, para o setor florestal, nota-se que o IQT pode ser influenciado pelo uso de dispositivos de acabamento do sulco, tais como a corrente, o rolo, diferentes tipos grades niveladoras, dentre outros. Entretanto, o uso destes dispositivos na escavadora ainda é inviável, pois estes equipamentos geram instabilidade ou atrapalham a operação de subsolagem.

Apesar da escavadora atingir qualidade satisfatória de profundidade, largura e mobilização do solo, Souza et al. (2018) salientam o seu baixo rendimento em campo na operação de subsolagem, o que causa o aumento do custo da operação, em relação ao subsolador acoplado ao trator de rodados. No entanto, a utilização da escavadora se justifica pelo fato do subsolador acoplado ao trator não possuir estabilidade para trabalhar em áreas acima de $17^{\circ}$ de declividade, o que aumenta os riscos de acidentes (Curti \& Costa, 2013). 


\section{CONCLUSÃO}

A operação de subsolagem com a escavadora hidráulica é considerada adequada para ser utilizada em áreas com 17 a $27^{\circ}$ de declividade, sendo obtidos valores dentro do recomendado para os indicadores de qualidade analisados, principalmente para as condições de solo úmido.

A condição de solo seco atinge as recomendações de subsolagem, porém, ocasiona o aumento do IQT, o qual por sua vez, ocasionou inconformidades no formato do sulco, o que está relacionado, principalmente, pela escavadora não possuir dispositivos de acabamento do sulco. Dessa forma, fica expresso a necessidade/importância de investimentos em novas tecnologias que reduzam o IQT e aumentem a eficácia da atividade em campo.

\section{AGRADECIMENTOS}

À Coordenação de Aperfeiçoamento de Pessoal de Nível Superior (CAPES) pela bolsa de pesquisa concedida. À Empresa Florestal Celulose Nipo-Brasileira - CENIBRA, pelo fornecimento dos dados.

\section{REFERÊNCIAS}

Almeida, C. X., Centurion, J. F., Freddi, O. S., Jorge, R. F., \& Barbosa, J. C. (2008). Funções de pedotransferência para a curva de resistência à penetração. Revista Brasileira de Ciência do Solo, Viçosa, 32(6), 2235-2243. http://dx.doi.org/10.1590/S0100-06832008000600003.

Alvares, C. A., Stape, J. L., Sentelhas, P. C., Gonçalves, J. L. M., \& Sparovek, G. (2013). Koppen'sclimateclassificationmap for Brazil. Meteorologische Zeitschrift (Berlin), 22(6), 711-728. http://dx.doi.org/10.1127/0941-2948/2013/0507.

Barros, J. W. D. (2001). Planejamento da qualidade do preparo mecanizado do solo para implantação de florestas de Eucalyptus sp. utilizando o método desdobramento da função de qualidade (QFD) (Dissertação de mestrado). Universidade de São Paulo, Piracicaba.

Baver, L. D., \& Gardner, W. H. (1972). Soil physics. New York: John Wiley.

Callegari-Jacques, S. M. (2003). Bioestatística: princípios e aplicações. Porto Alegre: Artmed.

Cassel, D. K. (1979). Subsoiling. Cropsand Soils Magazine, 32, 7-10.

Curti, L. S. P., \& Costa, M. R. (2013). Desenvolvimento e desafios da mecanização e da automação na CENIBRA. Série Técnica IPEF., 17(38), 29-37.

Empresa Brasileira de Pesquisa Agropecuária - EMBRAPA. Centro Nacional de Pesquisa de Solos. (1997). Manual de métodos e análise de solo (2. ed.). Rio de Janeiro: EMBRAPA.

Ferreira, D. F. (2011). Sisvar: um sistema computacional de análise estatística. Ciência e Agrotecnologia, 35(6), 1039-1042. http://dx.doi.org/10.1590/S1413-70542011000600001.

Fessel, V. A. G. (2003). Qualidade, desempenho operacional e custo de plantios, manual e mecanizado, de Eucalyptus grandis, implantados com cultivo mínimo (Dissertação de mestrado). Escola Superior de Agricultura "Luiz de Queiroz", Universidade de São Paulo, Piracicaba.

Figueiredo Filho, D. B., \& Silva Júnior, J. A. (2009). Desvendando os mistérios do coeficiente de correlação de Pearson (r). Revista Política Hoje, 18(1), 115-146.

Gadanha Júnior, C. D., Molin, J. P., Coelho, J. L. D., Yahn, C. H., \& Tomimori, S. M. A. W. (1991). Máquinas e implementos agrícolas do Brasil. São Paulo: Instituto de Pesquisas Tecnológicas do Estado de São Paulo.

Gava, J. L. (2002). Avaliação da qualidade do projeto do solo em áreas de Eucalipto plantado no sistema de cultivo mínimo do solo. Boletim de Pesquisa Florestal, 47, 55-58.

Hall, P. (1995). Mechanical site preparation using escavators. New Zeland Florestry, 31-35.

Lani, J. A., \& Bragança, S. M. (2017). Preparo, manejo e conservação do solo em lavouras de café conilon. In R. G. Ferrão, A. F. A. Fonseca, M. A. G. Ferrão \& L. H. Muner (Eds.), Café CONILON (2. ed., Vol. 1, pp. 303-325). Vitória: Incaper.

Leite, F., Santos, J. E. G., Lanças, K. P., \& Leite Júnior, J. B. (2011). Evaluation of tractive performance of four agricultural tractors in laterally in clined terrain. Engenharia Agrícola, 31(5), 923-929. http://dx.doi.org/10.1590/S0100-69162011000500010. 
Machado, T. M., Lanças, K. P., Fiorese, D. A., Fernandes, B. B., \& Testa, J. V. P. (2015). Estimativa de gasto energético da operação de subsolagem em profundidades variáveis. Revista Brasileira de Engenharia Agrícola e Ambiental, 19(11), 1121-1125. http://dx.doi.org/10.1590/18071929/agriambi.v19n11p1121-1125.

Minette, L. J., Silva, E. P., Souza, A. P., \& Hermsdorss, W. L. (2010). Avaliação ergonômica do protótipo de um motocoveador hidráulico, utilizado em atividades de silvicultura florestal. Engenharia na Agricultura, 18(6), 488-495. http://dx.doi.org/10.13083/reveng.v18i6.158.

Montebello, A. E. S., \& Bacha, C. J. C. (2009). Avaliação das pesquisas e inovações tecnológicas ocorridas na silvicultura e na produção industrial de celulose no Brasil. Revista de Economia e Sociologia Rural, 47(2), 485-517. http://dx.doi.org/10.1590/S0103-20032009000200008.

Pereira, D. P., Fiedler, N. C., Lima, J. S. S., Guimarães, P. P., Môra, R., \& Carmo, F. C. A. (2012). Eficiência da subsolagem na profundidade de preparo do solo em função da declividade do terreno. Cerne, 18(4), 607-612. http://dx.doi.org/10.1590/S0104-77602012000400010.

Queiroz-Voltan, R. B., Nogueira, S. S. S., \& Miranda, M. A. C. (2000). Aspectos da estrutura da raiz e do desenvolvimento de plantas de soja em solos compactados. Pesquisa Agropecuária, 35(5), 929-938.

Rossetti, K. V., \& Centurion, J. F. (2015). Ensaio de compactação em Latossolo cultivado com milho sob diferentes períodos de adoção de tipos de manejo. Agrária (Recife. Online), 10, 499-505.

Royston, J. B. (1983). Some techniques for assessing multivariate normality based on the Shapiro-Wilk W. Applied Statistics, 32(2), 121-133. http://dx.doi.org/10.2307/2347291.

Salvador, N., Benez, S. H., \& Mion, R. L. (2008). Consumo de combustível na operação de subsolagem realizada antes e depois de diferentes sistemas de preparo periódico do solo. Engenharia Agrícola, 28(2), 256-262. http://dx.doi.org/10.1590/S0100-69162008000200006.

Sasaki, C. M., \& Gonçalves, J. L. M. (2005). Desempenho operacional de um subsolador em função da estrutura, do teor de argila e de água em três latossolos. Scientia Forestalis, 69, 115-124.

Silva, A. P., Tormena, C. A., Dias Júnior, M. S., Imhoff, S., \& Klein, V. A. (2010). Indicadores da qualidade física do solo. In Q. Jong van Lier (Ed.), Física do solo (cap. 7, pp. 241-281). Viçosa: Sociedade Brasileira de Ciência do Solo.

Simões, D., Silva, M. R., \& Fenner, P. T. (2011). Desempenho operacional e custos da operação de subsolagem em área de implantação de eucalipto. Bioscience Journal, 27(5), 692-700.

Souza, G. S., Silva, S. A., Lima, J. S. S., Verdin Filho, A. C., Infantini, M. B., \& Krohling, C. A. (2018). Avanços na mecanização do cafeeiro conilon. Incaper em Revista, 9, 31-41.

Souza, M. J. H., Ribeiro, A., \& Leite, F. P. (2003). Balanço hídrico e caracterização climática de Guanhães, Nova Era e Rio Doce. In Anais do $13^{\circ}$ Congresso Brasileiro de Agrometeorologia (pp. 131-132). Santa Maria: S. B. A.

Theodoro, G. F., Golin, H. O., Silva, M. S., Rezende, R. P., \& Abreu, V. L. S. (2018). Influência de sistemas de preparo na manutenção da palhada e resistência do solo à penetração. Revista de Agricultura Neotropical, 5(2), 25-30. http://dx.doi.org/10.32404/rean.v5i2.2220.

Trindade, C., \& Melo, E. A. S. C. (2016). Controle de qualidade das práticas silviculturais. Série Técnica IPEF, 24(45), 21-25.

Volpato, C. E. S., Barbosa, J. A., \& Salvador, N. (2004). Operações adequadas de preparo do solo. Cultivar Máquinas, 3(33), 6-9.

Wang, H. B., Bai, W. B., Han, W., Song, J. Q., \& Lv, G. H. (2019). Effect of subsoiling on soil properties and winter wheat grain yield. Soil Use and Management, 35(3), 643-652. http://dx.doi.org/10.1111/sum.12524.

Author's contributions: FLC: escrita - investigação, análise formal, metodologia primeira redação, EMN: metodologia, análise formal, escrita - revisão e edição, LAM e NV: escrita - revisão e edição, TGA: recursos, validação, FPL: conceituação, administração do projeto, recursos. 